\title{
Outcomes of Balloon Kyphoplasty and Its Use in Pathological Vertebral Compression Fractures; a Single Centre Experience
}

\author{
Joseph Merola*, Thirayan Muthu and Zakier Hussain
}

Neurosurgery Department Waikato hospital Private bag 3200, Hamilton 3240, New Zealand

\begin{abstract}
Introduction: In recent years balloon kyphoplasty has become increasingly implemented in the treatment of vertebral compression fractures and has been shown to be safe and efficacious at long term follow up particularly for patients with metastatic disease to the spine. At Waikato hospital, New Zealand, we looked at our outcomes compared with current literature.

Methods: All patients who underwent balloon kyphoplastybetween 2008-2012 were included in the study and outcomes measured were pain scores and functional disability using the Oswestry disability index.

Results: 12 patients were included in the study and average pain scores both at rest and on activity improved post-operatively. Functional disability significantly improved at short and long term follow-up.

Conclusion: Balloon kyphoplasty is a safe and effective procedure and our results so far concur with current literature.
\end{abstract}

Keywords: Balloon kyphoplasty, vertebral compression fractures, vertebroplasty.

\section{INTRODUCTION}

Balloon kyphoplasty is a recognised approach for the treatment of vertebral compression fractures (VCFs) secondary to metastatic disease. It is a variation of vertebroplasty and involves the percutaneous introduction of inflatable bone tamps which create a cavity by compression of cancellous bone of the vertebral body. Bone cement is then injected into the new cavity [1]. This procedure is minimally invasive and aims to reduce pain, both short and long term, and improve function and quality of life [2]. Current evidence stands in favour of balloon kyphoplasty over non-surgical management of VCFs secondary to metastatic disease [2-5]. However its efficacy in osteoporotic VCFs has shown lack of statistical evidence at long term follow up despite excellent short term outcomes [6].

We present our series of patients who underwent kyphoplasty at Waikato hospital between 2008 and present time and looked at our outcomes as compared with the current literature. This paper is presented to keep relevant specialties abreast of current methods in Neurosurgery for the management of VCFs secondary to metastatic disease.

\section{METHODS}

We interrogated our prospectively gathered database to identify patients who had had balloon kyphoplasty done at Waikato hospital. All patients who underwent kyphoplasty were included and demographics, operative information (i.e. indication, title, date), duration of stay and complications were collected. Perioperative pain scores and the Oswestry disability questionnaire were used as measurable outcomes.

*Address correspondence to this author at the Neurosurgery Department Waikato hospital Private bag 3200 Hamilton 3240 New Zealand;

Tel: 02102555064; E-mail: merolaj@ doctors.org.uk
Patients were contacted and asked to complete the questionnaire over the phone or by email/post. All patients gave verbal consent.

\section{RESULTS}

12 patients were found on our database to have undergone kyphoplasty between 2008 and present time. Table 1 shows the patient details. All patients presented with back pain as a result of their underlying pathological process with radiologically proven vertebral body involvement.

As demonstrated by Table 2, patients either underwent balloon kyphoplasty in conjunction with another related procedure (e.g. laminectomy or stabilisation) or balloon kyphoplasty alone.

Pain scores were taken from the notes or observation chart when filled out. Pre- and post-operative scores were averaged for each patient at rest and with activity. Postoperative scores were taken the day of and prior to discharge. Table 3 shows the results of average pain scores for each patient.

This gave a total average pre-operative pain score at rest of 3.5 and on discharge 1. On activity pain scores preoperatively averaged 6.2 and on discharge 3.5 .

All patients were also contacted by telephone and asked whether they would be willing to fill in the Oswestry disability questionnaire. To date we had $92 \%$ response rate; 1 patient of 12 not answering the questionnaire. 3 patients (patients 2, 3 and 11) were deceased and were excluded from this point.

The total scores for each patient were summed up and a percentage score was calculated. For each section the total possible score is 5 . If the first statement is marked the section score $=0$ and if the last statement is marked the score 
Table 1. Patient details *Patient 10 was Initially Admitted with a Lumbar Spine Compression Fracture Initially Thought to be Due to Malignancy, However Following Vertebral Body Biopsy this was Shown to be Due to Chronic Osteomyelitis

\begin{tabular}{|c|c|c|c|c|c|}
\hline Pt & Age & Sex & Diagnosis & Follow up Time & Acute/ Elective \\
\hline \hline 1 & 64 & F & Metastatic follicular thyroid carcinoma & 1yr 10 months & Elective \\
\hline 2 & 71 & M & Metastatic prostate cancer & (Deceased) & Elective \\
\hline 3 & 45 & F & Metastatic squamous cell carcinoma & Elective \\
\hline 4 & 60 & M & Multiple myeloma 2 months & Elective \\
\hline 5 & 61 & F & Multiple myeloma & El 1 months & Elective \\
\hline 6 & 75 & M & Metastatic prostate cancer 1 months & Elective \\
\hline 7 & 58 & M & Multiple myeloma & Elective \\
\hline 8 & 72 & M & Metastatic prostate cancer & 3 months & Elective \\
\hline 9 & 76 & M & Metastatic renal cell carcinoma & Elyr 11 months & Elective \\
\hline $10^{*}$ & 71 & M & Lumbar spine osteomyelitis & Acute \\
\hline 11 & 34 & M & Metastatic testicular cancer & On Discharge & Elective \\
\hline 12 & 59 & F & Spinal lymphoma with osteopenia & & \\
\hline
\end{tabular}

Table 2. Operation Titles for Each Patient

\begin{tabular}{|c|l|}
\hline $\mathbf{P t}$ & \multicolumn{1}{|c|}{ Operation Title } \\
\hline \hline 1 & L3-4 laminectomy with L4 Kyphoplasty and L3-5 pedicle screw stabilisation \\
\hline 2 & Decompressive lumbar laminectomy of L2 with L2 kyphoplasty and L1-L3 pedicle screw fixation with vertebroplasty involving L1,L3 and L4. \\
\hline 3 & L3 decompressive laminectomy, open kyphoplasty + L2-L4 pedicle screw stabilisation \\
\hline 4 & Percutaneous T3, T6 + L4 kyphoplasty \\
\hline 5 & T6 and T9 balloon kyphoplasty \\
\hline 6 & T10, T11 and T12 kyphoplasty \\
\hline 7 & T8, T9, T11, L1 Vertebral kyphoplasty \\
\hline 8 & T3/T5, T11/12 + L1 kyphoplasty with T3-T5 decompressive laminectomy \\
\hline 9 & T10 to T11 decompressive laminectomy, T9 to T11 percutaneous pedicle screw fixation and T8 kyphoplasty. \\
\hline 10 & $\begin{array}{l}\text { L1-2 decompressive laminectomy with T11-12, L1-2-3-4 bilateral pedicle screw fixation and stabilisation + biopsy L1-2 + L1 kyphoplasty + L2 } \\
\text { vertebroplasty }\end{array}$ \\
\hline 11 & Emergency T2-T4 decompressive laminectomy with attempted vertebroplasty of T2 and T3. \\
\hline 12 & T7 to T10 kyphoplasty \\
\hline
\end{tabular}

Table 3. Average Pain Scores for Each Patient Pre- and Post-Operative While at Rest and on Activity. ND = Not Documented

\begin{tabular}{|c|c|c|c|c|}
\hline \multirow{2}{*}{ Pt } & \multicolumn{2}{|c|}{ At Rest } & \multicolumn{2}{c|}{ On Activity } \\
\cline { 2 - 5 } & Pre-op & On Discharge & Pre-op & 2 \\
\hline \hline 1 & 8 & 0 & 9 & 0 \\
\hline 2 & 2 & 0 & 4 & 3 \\
\hline 3 & 8 & 0 & 10 & ND \\
\hline 4 & 0 & ND & 4 & ND \\
\hline 5 & 2 & 2 & 3 & 2 \\
\hline 6 & 6 & 2 & 9 & 4 \\
\hline 7 & 0 & 2 & ND & 3 \\
\hline 8 & 3 & 0 & 3 & 8 \\
\hline 9 & 1 & 2 & 9 & 4 \\
\hline 10 & 6 & 0 & ND & 5 \\
\hline 11 & 7 & 0 & 7 & 4 \\
\hline
\end{tabular}


Table 4. Interpretation of Oswestry Disability Scores

\begin{tabular}{|l|l|}
\hline \multicolumn{2}{|c|}{ SCORE INTERPRETATION OF THE OSWESTRY LBP DISABILITY QUESTIONNAIRE } \\
\hline \hline 0-20\% Minimal Disability & $\begin{array}{l}\text { Can cope with most ADLs. Usually no treatment is needed, apart from advice on lifting, sitting, posture, } \\
\text { physical fitness, and diet. In this group, some patients have particular difficulty with sitting and this may be } \\
\text { important if their occupation is sedentary (typist, driver, etc) }\end{array}$ \\
\hline 20-40\% Moderate Disability & $\begin{array}{l}\text { This group experiences more pain and problems with sitting, lifting and standing. Travel and social life are } \\
\text { more difficult and they may well be off work. Personal care, sexual activity and sleeping are not grossly } \\
\text { affected, and the back condition can usually be managed by conservative means. }\end{array}$ \\
\hline 40-60\% Severe Disability & $\begin{array}{l}\text { Pain remains the main problem in this group of patients, but travel, personal care, social life, sexual activity } \\
\text { and sleep are also affected. These patients require detailed investigation. }\end{array}$ \\
\hline $60-80 \%$ Crippled & $\begin{array}{l}\text { Back pain impinges on all aspects of these patients lives both at home and at work. Positive intervention is } \\
\text { required. }\end{array}$ \\
\hline $80-100 \%$ & $\begin{array}{l}\text { These patients are either bed-bound or exaggerating their symptoms. This can be evaluated by careful } \\
\text { observation of the patient during the medical examination }\end{array}$ \\
\hline Data compiled from Fairbanks et al., 1980 &
\end{tabular}

is 5. If all 10 sections were answered (i.e. maximum score $=$ 50) then the total score is divided by 50 and multiplied by 100 to give a percentage. If a section was not answered or not applicable then that section was deducted (i.e. total maximum score $=45$ ).

The figure above demonstrates the pre- and postoperative Oswestry disability scores for each patient.

\section{DISCUSSION}

Vertebral compression fractures (VCFs) are usually asymptomatic and can present because of height loss or kyphosis[7]. The symptomatic patient however will classically present with sudden onset of back pain after minimal exertion such as bending down or lifting. This pain can radiate to the abdomen (so-called "girdle of pain") while radiation to the legs is rare. Pain duration can vary but any longer than three months should prompt further investigation [7].

Balloon kyphoplasty is a technique that involves the introduction of inflatable bone tamps into the vertebral body. Once inflated the bone tamps create a cavity that can be filled with viscous bone cement. It is significantly more expensive than vertebroplasty (a closely related procedure involving percutaneous injection of bone cement under fluoroscopic guidance without balloon inflation). The choice between kyphoplasty and vertebroplasty is a decision made by the surgeon [1].

Balloon kyphoplasty has been shown to be a safe and effective procedure for VCFs secondary to spinal metastatic disease. A 2 year prospective trial in 2008 demonstrated that mean pain visual analogue scales and Oswestry disability indices improved significantly after the procedure and that these findings were maintained up to 24months follow-up [4]. A systematic review and meta-analysis in 2009, Bouza et al., prompted further investigation into the use of balloon kyphoplasty since the literature showed level III evidence that the procedure was well tolerated and safe. The most recent study in 2011 (Cancer Patient Fracture Evaluation (CAFÉ) study) compared surgical intervention (balloon kyphoplasty) with non-surgical management of painful VCFs. This was a multi-centre and unblinded randomised controlled trial that enrolled 134 patients divided into nontreatment and treatment groups. The Rolland-Morris disability questionnaire was used to measure primary outcome. In the kyphoplasty group mean scores reduced from 17.6 to 9.1 at one month follow up and for the control group changed from 18.2 to 18.0 [3]. Another randomised controlled trial in 2009, Wardlaw et al., compared kyphoplasty with non-surgical management. This study used SF-36 to measure primary outcome and showed significant improvement in scores at one month for kyphoplasty as opposed to non-surgical management [2].

This study used the Oswestry Disability Index as a measurable outcome. It is one of the principal conditionspecific outcome measures used in the management of spinal disorders and as a measure of permanent functional disability. It is considered "gold standard" of low back functional outcome tools [8].

Although we cannot show similar results with significant numbers (due to lack of sample size) we feel that our results follow the trends set out in the literature. Average pain scores improved in the immediate post-operative setting by more than $70 \%$ at rest and $40 \%$ on activity. Unfortunately pain scores were not always well documented and so there were potentially more improved post-operative scores. Functional disability also showed improved trends at followup (Fig. 1). The interpretation of Oswestry disability scores is shown in Table 4. Six patients had improved disability following the procedure while two had anomalous results. Patient 1 reported a change from minimal disability to severe disability at follow-up (22months). This patient had kyphoplasty in conjunction with laminectomy and pedicle screw stabilisation and so her pain is difficult to attribute to a single factor. Patient nine remained in the same disability category (minimal) at follow-up (3 months) but quote "would definitely recommend" the operation.

It is worth noting that four of twelve procedures were stand-alone balloon kyphoplasty (i.e. not in conjunction with other procedures). For all four patients functional disability improved category from crippled/severe to moderate/minimal at follow-up $(3,6,7$ months and on discharge respectively).

As witnessed in our centre, balloon kyphoplasty is not always a stand-alone procedure and may not be attributable to the persistence or worsening of outcomes. Unsurprisingly not all patients will benefit from balloon kyphoplasty which is not without its complications. Well documented problems 
Pre \& post-operative Oswestry Disability scores for patients who have undergone Balloon Kyphoplasty

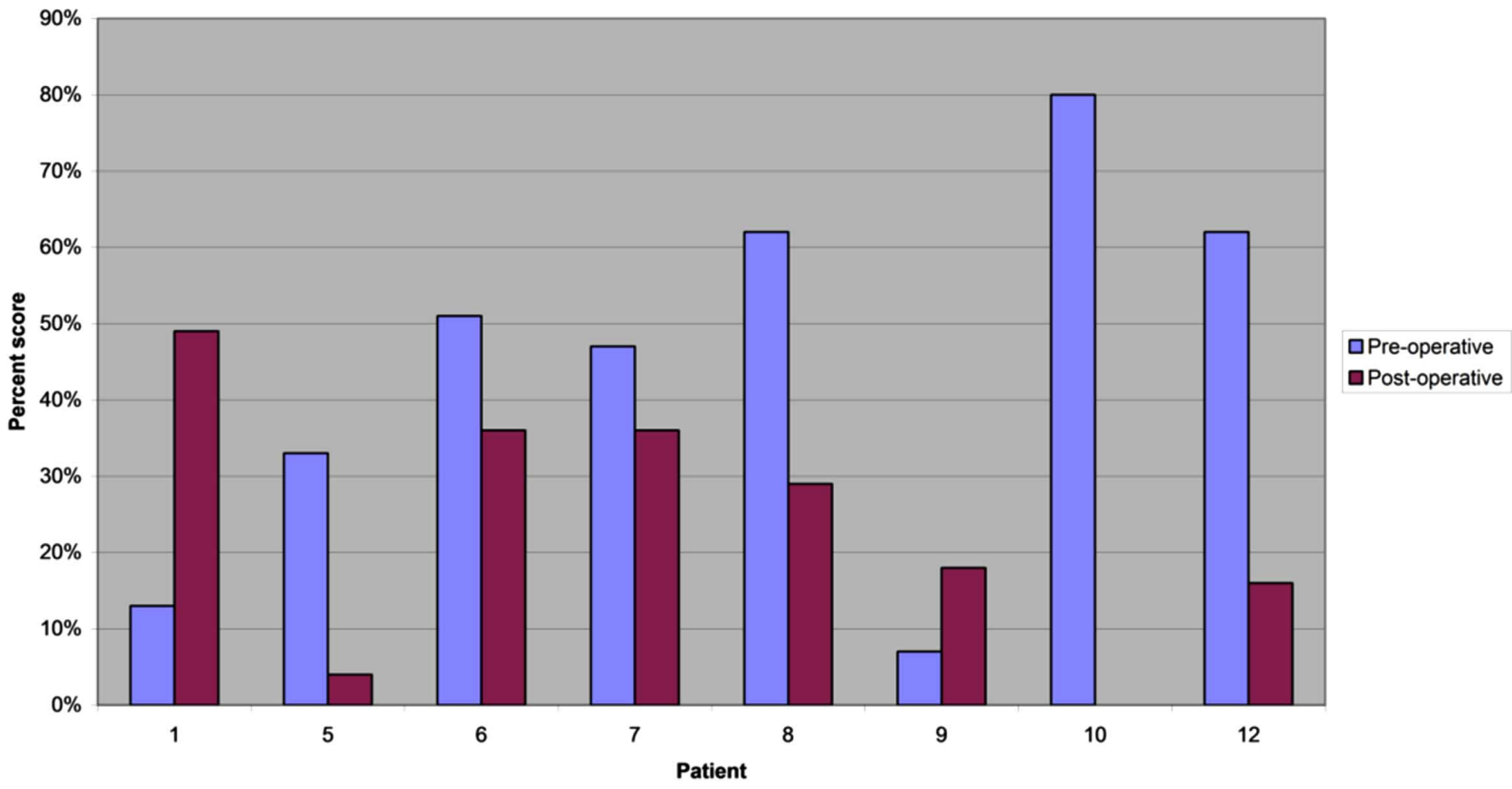

Fig. (1). Pre \& post-operative Oswestrey Disability scores for patients who have undergone Balloon Kyphoplasty.

include cement extravasation and new fractures. Other adverse events include balloon rupture, faulty puncture causing motor deficits, radiculopathy, paraesthesias or even paralysis. Less serious potential problems include infection or allergy [1]. Fortunately the incidence of complications is reportedly low [9].

Future research is aimed at reducing recognised complications and improving the clinical (i.e. pain and disability) and radiological outcomes intended by the procedure e.g. restoring vertebral body height or improving kyphotic deformity. Very recent literature reports new techniques to introduce the bone tamp or direct the flow of cement and reduce rates of leakage or new fractures $[10,11]$. Another study has looked at unilateral versus bilateral approaches and reported reduced operating times and radiation exposure for unilateral approaches with similar pain score, disability outcomes and complication rates as with bilateral approaches [12].

At our institution balloon kyphoplasty is increasingly being implemented in the treatment of VCFs secondary to metastatic disease. This study is presented as a means of keeping specialties up to date on what new techniques Neurosurgery can offer patients with VCFs in this setting.

\section{ACKNOWLEDGEMENTS}

I would like to thank Dr. Zakier Hussain and Dr. Thirayan Muthu, Neurosurgery department at Waikato Hospital for their continued support during the development of this paper.

\section{CONFLICTS OF INTEREST}

The authors confirm that this article content has no conflicts of interest.

\section{REFERENCES}

[1] Rajkumar SV. Treatment of the complications of multiple myeloma. In: Basow DS, Ed, UpToDate, Waltham, MA, 2012. Available at: http:www.uptodate.com/contents/treatment of the com-plications of multiple myeloma [Last Accessed on Jan, 2012]

[2] Wardlaw D, Cummings SR, Van Meirhaeghe J, et al. Efficacy and safety of balloon kyphoplasty compared with non-surgical care for vertebral compression fracture (FREE): a randomised controlled trial. Lancet 2009; 373: 1016-21.

[3] Berenson J, Pflugmacher R, Jarzem P, et al. Balloon kyphoplasty versus non-surgical fracture management for treatment of painful vertebral body compression fractures in patients with cancer: a multicentre, randomised controlled trial. Lancet 2011; 12: 225-35.

[4] Pflugmacher R, Taylor R, Agarwal A, et al. Balloon kyphoplasty in the treatment of meastatic disease of the spine: a 2 year prospective evaluation. Eur Spine J 2008; 17: 1042-8

[5] Bouza C, Lopez-Cuadrado T, Cediel P, et al. Balloon kyphoplasty in malignant spinal fractures: a systematic review and metaanalysis. BMC Palliative Care 2009; 8: 1-9.

[6] Boonen S, Van Meirhaeghe J, Bastian L, et al. Balloon kyphoplasty for the treatment of acute vertebral compression fractures: 2-year results from a randomised trial. J Bone Miner Res 2010; 26 (7): 1627-37

[7] Sheon R, Rosen HN, et al. Clinical manifestations and treatment of osteoporotic thoracolumbar vertebral compression fractures. In: Basow DS, Ed, UpTo Date, Waltham, MA, 2012. Available at: www.uptodate.com/contents/clinical-manifestations-and-treatmentof-osteoporotic-thoracolumbar-vertebral-compression-fractures [Last Accessed Jan, 2012].

[8] Niskanen RO. The Oswestry low back pain disability questionnaire a two year follow of spine surgery patients. Scand J Surg 2002; 91: 208-11

[9] National Institute for Health and Clinical Excellence (NICE). Interventional procedures overview of balloon kyphoplasty for vertebral compression fractures 2006. Available from at: http://guidance.nice.org.uk/IPG166. [Last Accessed April, 2012]

[10] Zarate B, Gutierrez J, Wakhloo AK, et al. Clinical evaluation of a new kyphoplasty technique with directed cement flow. J Spinal Disord Tech 2012; 25(3): 61-6

[11] Wilson DC, Connolly RJ, Zhu Q, et al. An ex vivo biomechanical comparison of a novel vertebral compression fracture treatment 
system to kyphoplasty. Clin Biomech (Bristol, Avon) 2012; 27(4): 346-53.
Wang Z, Wang G, Yang H. Comparison of unilateral versus bilateral balloon kyphoplasty for the treatment of osteoporotic vertebral compression fractures. J Clin Neurosci 2012; 19(5): 723-6.

(C) Merola et al.; Licensee Bentham Open.

This is an open access article licensed under the terms of the Creative Commons Attribution Non-Commercial License (http://creativecommons.org/licenses/by$\mathrm{nc} / 3.0 /$ ), which permits unrestricted, non-commercial use, distribution and reproduction in any medium, provided the work is properly cited 